\title{
DISCUSSION QUESTIONS AND ANSWERS (CHAPTERS 2-23)
}

\section{CHAPTER 2: TYPES OF CORPORATE FRAUD}

1. Define fraud.

Corporate fraud is an intentional act by one or more individuals to get an unjust advantage by using deception. Although no universally accepted definition is available, the major development banks define a fraudulent activity as any act or omission, including a misrepresentation, that knowingly or recklessly misleads or attempts to mislead a party to obtain a financial or other benefit or to avoid an obligation.

2. Identify the five elements of fraud.

Fraud has five major elements: (1) it involves two parties - a fraudster and a victim, (2) a fraudster knowingly or unknowingly facilitates a false statement, (3) a fraudster accepts the statement being false, (4) a victim relies on the false statement or presentation, and (5) reliance on the presentation results in a damage or risk of damage to a victim.

3. Explain the different types of corporate fraud.

Corporate fraud can be classified into three major areas: (1) asset misappropriations, (3) corruption, and (3) financial statement fraud. Asset misappropriations generally involve employees and include embezzlement, theft of cash or inventory, payroll fraud, or skimming revenues. Corruption can involve both an employee and management, whereas management usually commits financial statement fraud. Financial statement fraud involves falsifying financial information by "cooking the books" or misleading investors. The most popular financial statement frauds include 
fictitious revenue recognition, capitalizing expenses, channel stuffing, inadequate and misleading disclosure, concealed liabilities and expenses accelerating revenues, and deferring expenses.

4. Identify the major characteristics of financial statement fraud.

Financial statement fraud has four major characteristics.

- Fraud involves altering or manipulating financial statements, supporting documents, or business transactions.

- Financial statement fraud intentionally omits or mispresents events, transactions, accounts, or other material information from financial statements.

- Fraudsters knowingly misuse accounting principles and policies that are used to measure, recognize, report, and disclosure financial and economic transactions.

- Financial statement fraud involves intentionally inadequate disclosure of financials, accounting policies, and principles used to prepare financial statements.

\section{CHAPTER 3: HOW FRAUD OFFENDERS RATIONALIZE FINANCIAL CRIME}

1. Identify the three major drivers of fraud according to the fraud triangle.

The fraud triangle describes three factors that must exist in order for fraud to occur:

- a pressure or incentive that motivates an individual to commit fraud,

- a perceived opportunity to engage in fraud without detection, and

- the ability to rationalize the fraud to minimize feelings of guilt and maintain one's self-image of an ethical individual.

2. Explain how "normalization" operates in the context of fraud.

A fraudulent act can spread throughout an organization and become part of everyday practices through normalization. After an initial fraudulent act is committed, a lenient response from the organization can encourage the offender to rationalize in order to ease guilt resulting from 
the act and to forestall guilt for future corrupt acts. This response can lead to the behavior being repeated, with rationalizations becoming shared within the organization until the act becomes part of its routine practices.

3. Name the major types of rationalization identified in accounting research.

The main techniques used to rationalize behavior include

- displacement of responsibility,

- denial of responsibility,

- advantageous comparison,

- appeal to higher loyalties,

- condemning the condemners,

- diffusion of responsibility,

- denial of injury,

- denial of victim,

- metaphor of the ledger,

- postponement, and

- euphemistic labeling.

4. Describe the major personality characteristics associated with fraud offending.

Personality traits commonly connected with fraudulent behavior include positive extroversion, disagreeableness, neuroticism, overconfidence, lack of self-control, narcissism, Machiavellianism, and psychopathy.

5. Explain several ways to enhance the fraud triangle.

Revised models to enhance the fraud triangle include

- the fraud scale, which replaces rationalization with personal integrity;

- an organization-level fraud triangle, which includes charismatic leadership, management controls, and organizational culture;

- the ABCs of fraud (bad Apple, bad Bushel, and bad Crop syndrome), and M.I.C.E. (Money, Ideology, Coercion, and Ego).

6. Discuss what organizations can do to try to negate common rationalizations of fraud. 
Crime prevention initiatives should seek to dissuade people from contemplating crime by reducing their ability to rationalize before offending. Measures to develop such antirationalization programs remain underexplored and present an opportunity for future investigation.

\section{CHAPTER 4: ACCOUNTING PRINCIPLES AND CORPORATE FRAUD}

1. Identify the 10 accounting principles set forth by FASB.

FASB's 10 basic accounting principles are (1) monetary unit, (2) going concern, (3) full disclosure, (4) materiality, (5) economic entity principle, (6) conservatism, (7) cost principle, (8) revenue recognition, (9) matching principle, and (10) time period.

2. Identify several accounting principles that tend to be a major focus of corporate financial reporting fraud.

Instances of corporate financial reporting fraud vary among the 10 basic accounting principles. Nonetheless, firms tend to violate some principles more often than others. These principles tend to be revenue recognition, matching, economic entity principle, and conservatism.

3. Discuss why violations of the materiality principle are often difficult to identify.

Although the SEC, FASB, and IASB agree on a general definition of materiality, the definition does not indicate a specific amount as material. As a result, some vagueness exists in determining what is material. Thus, companies have substantial leeway in reporting what they view as material.

4. Explain the consequences of intentionally violating these principles.

Violating these principles can have consequences for several parties including managers, firms, and investors. When managers or employees violate these principles, they could lose their jobs, be subject to fines, and possible prison time. Violations are also likely to tarnish their reputations and affect their job prospects. Financial statement fraud resulting from violating these principles can have huge economic ramifications and potentially result in bankruptcy as evidenced by Enron and WorldCom. Economic losses associated with violating these principles can also affect investors as a result of declining stock prices. Investors, creditors, and others could lose confidence both in the firm's management and the 
reliability of its financial statements. Financial statement fraud resulting from violating accounting principles could also adversely affect debt markets, employees' retirement assets, and employment. To prevent further violations, regulators could engage in changing existing rules to make violations more difficult.

\section{CHAPTER 5: CORPORATE CULTURE AND FRAUD}

1. Define fraud and identify its main perpetrator.

Fraud is an intentional act by one or more individuals among management, those charged with governance, employees, or third parties, using deception to obtain an unjust or illegal advantage. Management is responsible for the assertions provided in financial statements, as signed by the board. Accordingly, management with board oversight is the chief perpetrator of financial statement fraud.

2. Define culture and explain who is responsible for a firm's culture.

Although culture has many definitions, it means shared values, beliefs, and norms when applied to firms. A firm's culture may be driven from the top-down (functionalist) or from the bottom-up (interpretative). The firm's management is responsible for setting controls, so generally culture is considered to be driven by "tone at the top."

3. Identify the attributes of corporate culture.

Corporate culture has four main attributes.

- Shared: Culture is the shared behaviors and values of a group.

- Pervasive: Culture permeates the organization.

- Enduring: Culture develops over the long term.

- Implicit: Culture is the instinctive, silent understanding for the group.

4. Discuss why researchers have difficulty in researching corporate fraud and the strategies used to mitigate these difficulties.

Fraud is difficult to research for several reasons including the

- breadth of the types of conduct;

- difficulty of detecting fraud in firms;

- generally collusive and covert nature of fraud; 
- multiple facets of perpetration in that multiple parties may conduct the fraud;

- lack of data providing reputable reported instances; and

- difficulty of measuring fraud.Strategies to mitigate these difficulties in research include

- using a binary variable that measures a fraud firm with the value of one and a nonfraud firm with the value of zero;

- examining one type of fraud only, such as financial statement fraud; and

- using publicly available or proprietary databases to identify fraud firms from events such as restatements, SEC enforcements, securities class action litigation, court reports, and media reports.

5. Discuss how to collect data on corporate culture if the goal is to research the possibility of an association with a firm's propensity to engage in financial reporting fraud.

Researchers conflate corporate culture with "tone at the top." Therefore, the task is to look for evidence as to the culture (i.e., values, norms, and beliefs) from several sources:

- the organization itself, such as websites, mission statements, awards, and media and

- the top management teams' behavior and attitudes. This task is likely to involve collecting primary data from those within the organization, such as through detailed interviews or surveys with employees or top managers. However, researchers often resort to proxies, which are measurable phenomena that approximate norms, values, and beliefs. Proxies may include criminal convictions for personal infractions or personal debt use of CEOs and senior managers.

\section{CHAPTER 6: CORPORATE GOVERNANCE AND FRAUD}

1. Discuss how board structure may reduce fraud.

Studies find that board independence is effective in reducing fraud likelihood. When mostly outside directors populate the board, they may 
do a better job in impartially monitoring management and firm operations. Research also shows that busy directors who pay attention to their reputations could also be effective monitors and may reduce fraud likelihood in their firms. Additionally, an audit committee composed of mostly outside directors and outside director stock ownership are important factors that may reduce fraud.

2. Discuss how director expertise may reduce fraud.

Directors who are finance or accounting experts are likely to be more adept at scrutinizing a firm's financial information, which suggests that they may be better equipped to detect signs of financial misrepresentations or fraudulent reporting than other directors. Audit committees consisting of mostly outside directors with at least one finance or accounting expert are associated with a lower probability of fraud occurring.

3. Explain how corporate culture may lead to fraud.

Employees beyond those holding top management positions may also commit fraud. Tone set by top management seems to be important. If top management emphasizes ethical values and acts accordingly, such behavior could set an example for firm employees. Research shows that a lack of internal trust is related to an increase in fraud likelihood. Evidence also shows how a corporate environment that pushes its employees to use aggressive accounting policies may increase fraud likelihood. Recent research also emphasizes an association between employee benefits and reduced fraud likelihood.

4. Discuss what fraud firms do after the revelation of fraud.

Once fraud is revealed, the firm's stock price declines substantially. Its reputation suffers and it loses the trust of its customers and investors. Thus, after fraud is revealed, firms take measures to rebuild their lost reputation and trust. They tend to implement various governance-related changes, including increasing the number of outside directors on the board, appointing finance and accounting experts to their boards, and improving their internal control systems.

\section{CHAPTER 7: NATIONAL CULTURE, LEGAL ENVIRONMENT, AND FRAUD}

1. Discuss what is national culture and through what channel it affects decisions. 
According to North (1991, p. 97), institutions are "humanly devised constraints that structure political, economic and social interaction." Culture impacts decisions through two channels. First, culture directly influences people's choices by shaping their motivations and perception of the world. Second, culture has an indirect influence through its impact on legal institutions, which affect individual and corporate decisions.

2. Explain the impact of national culture on corporate fraud.

Evidence has been mixed. Fraud is both positively and negatively related to power distance, individualism, uncertainty avoidance, and longterm orientation. Fraud tends to be positively related to the degree of masculinity and negatively related to local religion.

3. Explain how rules of law and legal enforcement affect fraud.

Countries with different legal origins have different legal rules and institutions. Common law countries are found to systematically outperform the civil law countries in terms of legal protection of investors. English common law countries have legal institutions signaling the strongest public and private enforcement of securities law. Legal enforcement imposes costs on firms and individuals engaged in misconduct. The expected cost of fraud is a function of the probability of getting caught and the sanctions imposed on alleged parties. Both public and private enforcements impose significant penalties on fraudsters.

4. Discuss the variation in enforcement intensities (cross-country and/or over-time) and the deterrence effect of legal enforcement.

To speak to the deterrence effect, examination of variation in enforcement intensities and the consequences of such variation is key. Evidence of cross-country differences leading to different financial outcomes provides indirect evidence that legal enforcement is effective in protecting investors, deterring fraud, and therefore contributing to the development of financial markets. Other research shows the importance of differences in legal environment at the domestic level, based on evidence across SEC regional offices and over-time changes in SEC enforcement intensities.

\section{CHAPTER 8: AGENCY THEORY AND FRAUD}

1. Identify the underlying concepts of agency theory in the Xerox case and link them to corporate fraud. 
Agency theory is based on two main axioms: (1) information asymmetry between principals and agents and (2) principal/agent interest divergence. Paul Allaire, Xerox's CEO, benefited from information asymmetry between managers and shareholders because Xerox was a company that made high investments in innovation and relied massively on intangible assets. These assets and costs are difficult to monitor. Allaire also had substantial and specific knowledge of the firm and its activities as he was its CEO for more than 14 years. Xerox offered its top management bonuses and stock options to align their interest with shareholders. However, this situation gave management an added incentive to meet stock market expectations at any cost.

2. Discuss the two kinds of moral hazard problems raised by information asymmetry between managers and shareholders.

First, the difficulty observing the managers' effort and the firm's complexity make linking the manager's action to the firm's outcomes problematic. Thus, managers can undertake fraudulent actions with a low probability of being sanctioned. Second, top management can manipulate their performance evaluation mechanisms by undertaking financial misreporting and ultimately initiating financial accounting fraud.

3. Discuss the link between the principal-principal agency problem and fraud.

Controlling shareholders are shareholders who hold large blocks of shares and can potentially select or influence the board of directors and/or the firm's managers. Opportunistic controlling shareholders can engage in corporate fraud and harm minority shareholders' interests through various forms of self-dealing transactions such as selling assets, goods, and services to controlled firms at high prices or transferring assets from the controlling firm to family members at low prices. Private access to information due to information asymmetry can also facilitate corporate fraud in concentrated firms.

4. Explain how the separation between controlling rights and cash flow rights may increase interest divergence between different types of shareholders.

Ownership and control can be separated to the benefit of controlling shareholders, mainly with a pyramidal structure. Holding a firm through successive intermediate holding entities allows controlling shareholders to have excess voting rights to their cash flow rights and to avoid the full cost of decisions harming firm prospects. Therefore, controlling shareholders 
may take self-serving decisions at a lower cost. Unlike minority shareholders, controlling shareholders have private benefits that may lead to diverting resources.

\section{CHAPTER 9: EXECUTIVE INFLUENCE AND FRAUD}

1. Discuss the primary reasons executives commit fraud.

Executives commit fraud for various reasons. A primarily reason is for personal gain. For instance, executives may be compensated in such a way that they benefit from substantial increases in firm financial performance (e.g., bonus structure) or large increases in the company's stock price (e.g., equity compensation gains in value). This compensation structure may then prompt them to misreport the firm's performance in order to hit bonus targets or option exercise prices. Another reasons executives may also commit fraud is because they feel pressure to continually perform to appease investors and therefore may try to identify means, often fraudulent, to enhance the financial statements of their firms.

2. Explain how equity compensation may influence top executives to commit fraud.

Equity compensation may influence top executives to commit fraud because they are earning a larger portion of their salary through stock holdings. Therefore, they may seek to make decisions to drive results in the short or near term - the period of time in which their decisions are likely to affect the executive's power, influence, and monetary gain. Focusing on the short term, however, may prevent executives from taking a longer-term approach that would provide greater benefit of the overall organization and its longevity as a going concern. This nearsightedness may lead them to engage in fraudulent activity, which may involve manipulating financial metrics and reporting to increase a company's stock price and subsequently their net worth due to the outsized equity holdings in relation to other forms of compensation.

3. Discuss agency theory and how corporate boards of directors can lessen the risk associated with the principal-agent problem.

Agency theory is the relationship between two parties whereby one party (the principal) is hired by the other party (the agent) to act on its behalf to perform an action or service. Corporate boards of directors can mitigate against the risk that the corporate executive, acting as the 
principal on behalf of the shareholders, deviates from the shareholder goals by structuring the compensation package to align incentives and reduce moral hazard. Additionally, the board should consist of a balance of inside and independent directors to ensure both in-house expertise and objective monitoring capabilities.

4. Discuss the various roles that the executive lawyer plays.

The executive lawyer sits at a unique crossroads in the firm's governance structure. On one hand, the corporate lawyer serves as a gatekeeper and monitor on firm activities and hence has a fiduciary responsibility to shareholders. On the other hand, the corporate lawyer is tasked with advisory and strategic responsibilities to the firm. The executive lawyer also receives incentive compensation and faces a degree of short-termism similar to management.

5. Identify how the board of directors can reduce the risk of fraudulent behavior among members of the executive management team.

To lessen the risk of fraudulent behavior among members of the executive management team, the board of directors should include independent directors consisting of former executives and experienced managers. These individuals are likely to have a deep understanding of the liabilities and the oversight necessary to provide transparency to shareholders. Independent board members can also bring fresh ideas and strategic vision that can help influence the managerial compensation structure. Because the CEO has less influence over the independent versus nonindependent directors, the firm may be less susceptible to manipulative practices.

6. Discuss the effect that connectedness of the executive may have on engaging in fraudulent behavior.

As business and social worlds collide resulting in more active and increasing connectivity among colleagues, businesses must continuously consider the impact that such connections and engagements have on the propensity of executives to enable or perhaps directly engage in fraudulent behavior. Nonprofessional connections tend to result in a greater propensity for executives to engage in fraudulent behavior, whereas professional connections mitigate the risk. Nonprofessional connections provide a level of comfort or moral flexibility creating a nebulous area leaving open for interpretation of what is right and wrong. In contrast, professional connections provide some layer of oversight and business metrics on the executive manager and by extension reduce the propensity for engaging in fraudulent behavior. 


\section{CHAPTER 10: CORPORATE POLITICAL CONNECTIONS AND CORRUPTION}

1. Discuss how regulators, NGOs, and media outlets attempt to provide transparency of political connections and fraudulent activities.

Government agencies, such as the FBI, have improved their dissemination of fraudulent acts including corruption in recent years. The Internet, in particular, has improved access to these data providing further transparency. NGOs and other not-for-profit organizations have made public data more accessible through their websites. For example, OpenSecrets.org aggregates data from several sources including the US Senate website to make the data more user-friendly. It also provides useful and provocative summary statistics. Finally, corruption and positive externalities due to political connections make for interesting news. To that end, many media outlets now "break" or report on stories of corruption and other effects of political connections.

2. Explain how stock market-based tests of political connections improve understanding of the value of these connections.

Several examples are available of how the stock market responds to the value of political connections. Studies using market response tests can isolate an event that affects a firm's political connections, increasing or decreasing the value of those connections. Efficient stock markets can quickly incorporate new information into stock prices. Therefore, an increase or decrease in the stock price, in response to a political event, effectively values the political connection. For example, if stock price increases when a connected political candidate wins an election, an inference is that stock market participants value the political connection.

3. Discuss how political connections could benefit firms.

The empirical literature identifies several benefits to political connections for firms. These benefits include increased procurement contract awards and preferable contract characteristics, greater loan approval success from government owned banks, improved access to government bailout funds, decreased SEC enforcement, and lower fraud detection rates.

4. Discuss whether corruption can have a positive effect on firms.

Some evidence suggests that corruption can "grease the wheels" of an otherwise immobile bureaucracy. This theory proposes that bribes to government officials are an efficient outcome if these bribes allow the firm 
to operate more effectively in its environment. Without the ability to engage in corrupt activities the firm would be rendered unable to operate.

5. Identify the main issue with estimating causal effects for nation-wide corruption and discuss how researchers deal with this problem.

The primary issue with studying corruption at a national level is that changes in corruption may be correlated with other macroeconomic changes. For example, if corruption decreases at the same time as a reduction in trade barriers, then disentangling the economic effect of decreased corruption from that of reduced trade barriers can be difficult. To overcome this issue, researchers tend to focus on within-country studies of corruption and seek out settings in which corruption, or corruption enforcement, randomly varies such as Brazilian anticorruption campaigns.

\section{CHAPTER 1 1: THE SPILLOVER IMPACT OF CORPORATE FRAUD ON PEER FIRMS}

1. Discuss why fraud committed by a firm can have a spillover effect for other firms.

Corporate fraud is not necessarily a firm specific or idiosyncratic event. When a firm's fraud is revealed, stockholders and lenders may suspect that other firms are engaged in similar activities, or they may revise their expectations about the industry's future prospects. Hence, corporate fraud can affect peer firms' stock prices or lending conditions. A firm's fraudulent behavior can seduce another firm to follow suit. Given these possibilities, corporate fraud committed by a firm can have spillover effects on peer firms.

2. Explain the circumstances under which a firm is likely to imitate another firm's fraudulent practices.

When a firm becomes aware of corporate fraud committed by another firm, it may get involved in similar practices if it notices that either the fraud is not revealed or the impact of fraud revelation is small. Hence, if the peer firm sees that the benefit of committing fraud is higher than its cost, it may decide to engage in fraudulent practices. Situations exist when a firm is highly likely to get into fraudulent behavior such as when a large fraction of firms in the same industry are involved in fraudulent activities, or when it shares a common director with a fraudulent firm. 
3. Discuss how a firm's fraudulent activities can distort its peers' operating and financing decisions.

When a firm is engaged in fraudulent practices and peer firms are unaware of the fraud, peer firms can be misled by the actions taken or information provided by the fraudulent firm. For example, when a firm reports inflated but fraudulent performance, peer firms may interpret this situation as a positive sign for the industry and can make distorted operating and financing decisions.

4. Explain how a firm committing fraud can affect the stock prices of peer firms.

When a firm's fraud is exposed, investors can become skeptical about the quality of information of peer firms, which can negatively affect their stock prices. Additionally, the revelation of fraud can motivate investors to negatively revise their outlook for the industry resulting in the stock prices of peer firms experiencing downward pressure. On the other hand, investors may predict that the peer firms' financial prospects become better upon the revelation of a fraud committed by a rival firm. They may think that customers of the fraudulent firm are likely switch to peer firms, thereby resulting in investors revising the equity valuation of the peer firms upward.

5. Discuss how lenders respond to the exposure of the fraudulent activities of an industry peer.

Similar to stockholders, lenders may believe that peer firms are involved in fraudulent activities when the fraud committed by a firm is exposed. Hence, lenders may adjust the borrowing conditions of peer firms. Evidence shows that lenders increase the loan spread for peer firms after the revelation of fraud committed by a firm. Evidence also shows an impact on nonprice loan terms such as covenants.

\section{CHAPTER 12: CROWDFUNDING WITHOUT CROWD- FOOLING: PREVENTION IS BETTER THAN CURE}

1. Discuss why the rate of detection of project fraud on crowdfunding platforms remains low.

Several reasons explain why the fraud detection rate on crowdfunding platforms remains low. First, some platforms include many proposed projects. As a result, they do not filter out questionable projects, leaving some fraudulent cases. In this context, the crowdfunding community can help to 
detect them. Indeed, the strength of social networks and the notion of crowd wisdom are countermeasures to fraudulent behavior. Second, the small amount involved coupled with cumbersome legal procedures can be a barrier for individual contributors to report suspicious and/or fraudulent entrepreneurs. Third, proving an intentional scam is difficult. Despite prescreening proposed projects by some platforms, some cases of fraud remain undetected.

2. Explain why the notion of trust is important in crowdfunding.

The notion of trust is a cornerstone of crowdfunding for several reasons. For example, contributors neither personally know the project holder to whom they give their money nor have guarantees such as those provided by a bank or investors investing in a listed company. Additionally, contributors rely entirely on the entrepreneur's honesty and must be able to place their trust in the statements and information provided by the entrepreneur.

3. Summarize the characteristics associated with both entrepreneurs and their crowdfunding campaigns that may be useful to detect fraud in crowdfunding.

Various studies highlight common characteristics of fraudulent crowdfunding behavior. These characteristics relate to the entrepreneur (e.g., crowdfunding experience, presence on social networks, and credit history) and the fundraising campaign (e.g., number and amounts of contribution categories and campaign duration). Platforms and contributors can use these features to establish effective detection mechanisms against fraud.

4. Discuss the means available to various crowdfunding stakeholders such as platforms, contributors, and legislators to fight fraud on crowdfunding platforms.

The fight against fraud in crowdfunding can be waged by platforms, contributors, and legislation. Platforms can establish systematic procedures for selecting and auditing proposed projects. Contributors can report fraudulent campaigns. Legislators can set up regulations and mechanisms specific to crowdfunding such as the private insurance.

\section{CHAPTER 13: CORPORATE WHISTLEBLOWING: TOWARD A REGULATORY APPROACH}

1. Discuss whether giving a financial incentive to whistleblowers is good public policy. 
Some researchers and policy makers contend that financial incentives for whistleblowers are unnecessary. They suggest that providing financial incentives may weaken companies' internal reporting mechanisms or lead to frivolous tips. Despite these arguments, evidence suggests that financial incentives can be useful in encouraging whistleblowers. Often whistleblowers have already attempted to alert their company to the problem and been unsuccessful. Minimum thresholds for company sanctions that must be reached before paying out incentives to whistleblowers can also be effective in limiting frivolous tips.

2. Explain whether financial incentives are truly necessary to ensure an effective whistleblowing program.

Not all whistleblowing programs contain financial incentives. For example, the UK program was introduced without financial incentives, describing them as costly, ineffective, and counterproductive. In general, programs without financial incentives focus predominantly on protecting whistleblowers from retaliation. In some cases, these programs extend coverage to individuals beyond employees alone such as contractors or relatives.

3. Discuss how to deal with whistleblowers who bear some responsibility on the issues on which they tip and whether taking away or reducing their award is too much of a deterrent for them to come forward.

In many regimes, whistleblowers who are convicted of a criminal offense in relation to the matter on which they are tipping are ineligible to receive a financial award. For individuals who are less culpable, some whistleblowing programs reduce the award provided or offer a maximum payout value. The information benefit gained by including culpable individuals in rewards must be balanced against potential negative consequences such as undermining the integrity of the whistleblowing program.

4. Describe how to protect whistleblowers from retaliation from their employers.

Several steps can be taken to encourage whistleblowing without threat of retaliation. These steps include mandating internal whistleblowing policies for all companies with regular reports on whistleblowing activities provided to the board. Additionally, protection from retaliation may be offered to a wide range of individuals including employees, contractors, interns, and relatives. Tippers may choose to remain anonymous. Finally, whistleblowers may be able to bring forward a civil case against their employer if retaliation occurs. 


\section{CHAPTER 14: FORENSIC ACCOUNTING AND FRAUD DETECTION}

1. Discuss how a consulting expert and a testifying expert differ.

Forensic accounting encompasses both investigative services and litigation support services. Forensic accountants act as either consulting experts in an investigation or testifying experts in a legal matter. Consulting experts help counsel build a case and advise counsel as part of the investigative team. In this role, their work and communications with counsel can come within the attorney-client privilege, attorney work product. A company's outside counsel hires forensic accountants providing litigation support services as testifying experts. Testifying experts give opinions in court based on their review of the evidence, but privilege does not apply.

2. Explain the differences between financial statement audits and fraud examinations.

The scope, timing, and nature of financial statement audits and fraud examinations differ. Financial statement audits are a review for compliance with generally accepted accounting principles (GAAP) or International Financial Reporting Standards (IFRS). Financial statement audits are nonadversarial and exist to provide stakeholders with confidence - not to find fraud. The auditors sample the data and do not investigate every transaction or specifically look for fraud.

Fraud investigations require a complete review of the evidence. Although auditors conduct sample testing as part of their work, sampling is an ineffective investigative technique. Fraud examinations are nonrecurring engagements. The goal is not to give an opinion but to report on whether fraud exists and to determine who is responsible. Due to the seriousness and sensitivity around the issue, fraud investigations can be adversarial.

3. Discuss the importance of using investigation techniques that are unlikely to arouse suspicion among possible perpetrators.

When conducting a fraud investigation, using techniques that are unlikely to arouse suspicion is important otherwise perpetrators may stop committing the fraudulent out of fear of being caught and engage in hiding or destroying crucial evidence. Although stopping the fraud is 
desirable, the destruction of evidence impedes prosecuting the fraud and calculating financial damages. Forensic accountants should interact with company employees in a way that does not draw attention or suspicion. For example, instead of using such words as "investigation" or "fraud," they should refer to a consulting project.

4. Identify the strengths and weaknesses of using an inductive approach to proactively search for fraud.

Inductive reasoning always begins with a conclusion and when taking an inductive approach to investigating fraud, the first step is to identify the frauds that may be occurring. The forensic accountant then applies inductive search methods to test for fraud. Companies may prefer taking an inductive approach to searching for fraud because this approach has a low cost. However, inductive investigation methods produce so much data or "red flags" that investigating all of them is often too costly. Therefore, forensic accountants often prefer a deductive approach, which is a more holistic approach to finding fraud. The deductive approach follows a six-step process that starts with acquiring a good understanding of the business, identifying the types of frauds that could exist in the company, and determining the indications of the most likely frauds. Then the forensic accountant can use databases and other automated tools to search for those signs, examine the results, and investigate symptoms to determine their causes.

5. Define internal controls and provide examples of internal controls that can help prevent and deter fraud.

Internal controls are methods by which a company safeguards its assets and provides reasonable assurance about the reliability of the company's financial reporting, effectiveness and efficiency of its operations, and its compliance with appropriate laws and regulations. Segregation of duties, sound policies and authorizations, independent checks, and physical safeguards are critical elements in reducing the potential for fraud.

\section{CHAPTER 15: CYBER SECURITY AND CORPORATE FRAUD}

1. Explain the types of cyber fraud.

Cybercrime or cyber fraud encompasses a range of illegal or illicit activities committed using a computer over telecommunications networks. 
The most important categories of cyber fraud include creating illegal or illicit online markets, stealing trade secrets and intellectual property, distributing and using ransomware and other malicious software, and offering cybercrime as a service.

2. Explain how the most common types of cyber fraud occur.

Cybercrime occurs when criminals can gain unauthorized access to computer networks, usually through identity theft. The methods for engaging in identity theft include social engineering exploits such as phishing, spear phishing, and whaling.

3. Discuss how cyber fraud can differ by industry.

Different industries offer diverse targets for criminals. In financial services, the target typically has access to the payment system. Retailers are usually targets for identity theft to access online accounts and make unauthorized purchases. Manufacturers and industrial companies are subject to the loss of intellectual property or sabotage by disgruntled employees. Healthcare providers are prime targets for the theft of personally identifiable information such as health records.

4. Describe the direct and indirect costs associated with cyber fraud.

The indirect costs associated with cyber fraud may be difficult to quantify and may exceed the direct cost of the crime. Examples of indirect costs include the cost of forensic investigation, breach notification, postbreach client protection, attorney's fees, increased regulatory scrutiny or fines, increased cyber security, and the loss of business. Direct costs include the additional cost to improve the organization's information security infrastructure to guard against future breaches and the cost of the ransom if a breach occurs.

5. Discuss the key source of cyber fraud and how to avoid it.

The key source of cyber fraud is the ability of the criminal to gain unauthorized access to the target IT systems. Although using technology to safeguard and monitor IT systems is a necessary step, most successful breaches occur because of human error. The various social engineering techniques allow the theft of network credentials that enable introducing malware to perpetrate the fraud. Cyber security training and improving the awareness of users to recognize and avoid these attacks are good ways to avoid cyber fraud. 


\section{CHAPTER 16: LAW ENFORCEMENT AGENCIES AND CORPORATE FRAUD}

1. Identify the three primary responsibilities of the Corporate Fraud Task Force as outlined in Executive Order 13271 issued in 2002.

President George W. Bush's Corporate Fraud Task Force was tasked with three primary responsibilities:

- prove direction for the investigation and prosecution of white collar crimes,

- make recommendations to the Attorney General on how to better allocate US Department of Justice resources to catch white collar offenders,

- and make recommendations to the President through the Attorney General on how to increase cooperation between law enforcement agencies and what rules and polices needed revision to better combat financial fraud.

2. Explain the role of the Assistant US Attorney (AUSA) and the DOJ Trial Attorney in prosecuting fraud cases.

AUSAs and Trial Attorneys are the DOJ's front-line prosecutors. They open grand jury investigations, assemble and lead a team of special agents who work alongside the prosecutor to development evidence for presentation to a grand jury, and present an indictment before the grand jury, if warranted. AUSAs and Trial Attorneys also lead the prosecution of the defendant after indictment.

3. Describe a grand jury's composition and function.

A grand jury is an investigative body that meets in secret and is composed of between 16 and 23 members who are US citizens. It hears evidence presented by the prosecutor and votes to approve or reject the indictment presented by the prosecutor. Grand juries can compel the production of documents and witness testimony.

4. Describe the roles played by the SEC and PCAOB in combating corporate fraud.

The SEC and PCAOB are regulatory agencies that may act separately or in conjunction with the DOJ. The SEC may protect the financial system by barring issuers of securities from selling securities through the use of 
stop orders. The PCAOB may bar certified public accountants and public accounting firms from auditing publicly traded companies by using disciplinary orders.

\section{CHAPTER 17: FINANCIAL STATEMENT FRAUD: MOTIVATION, METHODS, AND DETECTION}

1. Identify the factors that separate earnings management and other forms of accounting manipulation from financial statement fraud and indicate where the line separating the two should be drawn.

The line separating earnings management and other forms of accounting manipulation is blurred. However, "routine" manipulation is rarely subject to penalties, criminal or civil. In theory, deliberate efforts to dress up or bias the financial statements is a form of financial fraud, but several markers need to be present before legal authorities become involved. Manipulation is apt to become "fraud" when documentation is doctored to support the bogus numbers. An example is when a reporting entity makes up revenue and creates fictitious invoices to back up the revenue. Another important marker is the damage caused to other parties. Companies and their senior management are more likely to be charged with fraud when investors, employees, or suppliers suffer substantial losses. A third marker is present when senior managers personally profit from the manipulation.

2. Discuss the responsibilities that auditors have in detecting and reporting fraud and whether auditors are "watchdogs" or "bloodhounds."

Auditors should be both watchdogs and bloodhounds. Auditors have difficulty contending that they are merely watchdogs when the public suffers from a massive accounting fraud. Auditors exist in part, to protect the public from such conduct. Increasingly, auditors of the big firms acknowledge this responsibility, but they appear to have done so reluctantly.

3. Discuss whether gender is a useful discriminator in the detection of fraud.

Gender may have a role to play as a useful discriminator in detecting fraud. The major factor may be the male hormone, testosterone. High levels of testosterone are associated with more aggressive and risk-taking behavior. Accounting fraud is one manifestation of this behavior. Therefore, the absence of testosterone may result in a tendency toward more honest accounting. 
4. Are there instances in which deliberate bias in accounting numbers can be justified from an ethical perspective and explain what makes them different from other examples of management bias.

The simple answer is no, but reality is a bit more complex. Some have sympathy for companies that dress up the financials to avoid violating debt covenants. Going into technical default on a loan can be expensive. As long as the debt is serviced completely and on time, one could argue that the lender has suffered no harm. However, even in this case, the loan's riskiness has increased without the lender's knowledge, so perhaps the lender suffered damage after all.

5. Explain why whistleblowing is still the most common way that accounting fraud is discovered despite the many tools available to detect accounting fraud.

Whistleblowers are so much "closer to the action" than analysts, lenders, investors, and others who are trying to detect unscrupulous accounting. Close proximity nearly always gives them access to information that others do not have and could not be expected to have.

\section{CHAPTER 18: ACCOUNTING SCANDALS: ENRON, WORLDCOM, AND GLOBAL CROSSING}

1. Identify the type of corporate fraud discussed in this chapter.

The corporate fraud discussed in this chapter primarily relates to accounting irregularities and misstating financial statements. Specifically, improper use of SPEs, capitalizing expenses, and aggressive revenue recognition.

2. Discuss the accounting fraud perpetrated by the executives at Enron, WorldCom, and Global Crossing and discuss how it was uncovered and who uncovered it.

Enron's primary fraudulent activities relate to its improper use of SPEs. Enron's SPEs contained large amounts of debt that Enron fraudulently omitted from its consolidated balance sheet. The company obscured the actual equity investors had in the SPEs to give the impression that the SPEs should not be consolidated with Enron. In reality, the actual SPE investors were executives at Enron and generally accepted accounting principles required Enron to consolidate with the 
SPE, which Enron failed to do. Sherron Watkins uncovered the fraud while reviewing Enron's use of SPEs.

WorldCom improperly recorded expenses as assets by capitalizing its expenditures. GAAP requires expensing of an expenditure when it does not have a life exceeding one year. GAAP allows capitalizing an expenditure as an asset when the expenditure benefits more than one year such as when purchasing machinery and equipment. By improperly capitalizing expenditures, WorldCom overstated net income on its income statement and overstated assets on its balance sheet giving the impression that the company was healthier than it really was. Cynthia Cooper uncovered the fraudulent activity when performing a routine internal audit of WorldCom's capital expenditures.

Global Crossing's fraudulent activities involved the improper recording of revenue from indefeasible rights of use (IRUs). The SEC and FBI uncovered this improper recording during their investigations of the company's attempts to inflate its stock price.

3. Discuss the role of SPEs in corporate fraud at Enron.

SPEs are legitimate accounting vehicles set up by the parent firm to segregate specific assets and liabilities of the SPE with the intent to lower the cost of debt to the parent firm. To be considered off-balance sheet, and hence avoid consolidation with the parent, the SPE must satisfy various conditions. The parent firm can set up the SPE to appear that it satisfies the conditions for nonconsolidation and thus avoid reporting liabilities on the parent's consolidated balance sheet. However, management of the parent company can obscure the true set up of the SPE and in reality the SPE does not satisfy the conditions for nonconsolidation and should be consolidated with the parent company.

4. Discuss how the Sarbanes-Oxley Act of 2002 can reduce corporate fraud.

SOX can reduce corporate fraud by raising corporate governance standards designed to improve the accuracy and reliability of corporate disclosures. These standards are intended to enhance the accountability, integrity, and transparency of companies listed on the stock exchanges.

Additionally, Section 404 of SOX requires annual reports to include the company's own assessment of internal controls over financial reporting and an auditor's attestation of the effectiveness of such controls. 
Section 404 adds another level of control (the auditor's attestation) over the reporting of companies financial statements.

5. Identify the consequences to employees, executives, and shareholders from corporate fraud.

The consequences of corporate fraud can be felt at the employee, executive, and shareholder level and can reverberate through the capital markets. Employees often lose their jobs, their severance packages, and their pensions. Authorities may find executives to be personally responsible for fraudulent activities resulting in prison terms, fines, or both in addition to losing their position within the firm. Shareholders can suffer a substantial and unanticipated decline in their wealth as the firm's stock price plummets as a result of the fraud. Finally, financial market participants may question the integrity of financial reporting and oversight thus leading to the efficiency of capital markets.

\section{CHAPTER 19: PANAMA PAPERS AND THE ABUSE OF SHELL ENTITLES}

1. James Jensen owned and operated Capital Car Finance, an automobile title loan business in Atlanta, Georgia. He also owned Cash Auto Sales, an entity that managed "auto club" membership services for Capital Car Finance. Jensen filed for Chapter 13 bankruptcy due to numerous outstanding money judgments against him. In the filing, he claimed assets between $\$ 0$ and $\$ 50,000$ and liabilities between $\$ 500,000$ and $\$ 1,000,000$. Before filing for bankruptcy, Jensen transferred $\$ 1.5$ million to an investment account titled in his and his wife's name. He also purchased a \$2.0 million cashier's check made out to Same Day Windshield, an LLC exclusively in his wife's name with no substantial assets. Jensen did not disclose these transactions during bankruptcy. Explain whether Same Day Windshield is a shell company and whether this action is an abuse of an LLC entity.

Yes, Same Day Windshield is a shell entity that Jensen formed to commit a crime. Asset hiders form various types of domestic and foreign entities, including LLCs, to hide assets. Because Same Day has no substantial assets and Jensen used it to conceal assets in a bankruptcy, it is a shell entity and an abuse of the LLC form. 
2. One obstacle to achieving practical or actual transparency of beneficial ownership is that ownership transparency requirements vary vastly between jurisdictions. Discuss what could be done to overcome this obstacle.

Ownership transparency can be achieved by using a central registry that collects, retains, and verifies information to determine beneficial ownership of all types of entities. Information contained in the central registry could include the name and address of the entity, its type, name and address of the registered agent, name(s) of the legal and beneficial owner(s), and its officers and directors. Jurisdictions such as Wyoming and Nevada with strong secrecy laws offer minimal reporting and disclosure requirements. The benefits these states receive from these laws include large revenues generated from incorporation fees and annual corporate and other entity renewal fees.

3. Identify the characteristics of a shell entity and how it differs from a legitimate business entity.

The characteristics of a shell entity may include

- no substantial assets or ongoing business activity;

- no physical presence besides a mailing address;

- no employees;

- often, other shell entities are registered at the same building;

- formed with a generic purpose; and

- privately owned.

4. Although tax evaders and money launderers have used private interest foundations (PIFs), discuss some possible benefits or positive uses of these vehicles.

A PIF offers several benefits. It follows the letter of wishes outlining a foundation's present and future goals and the founder and beneficiaries maintain confidentiality of assets owned and eventually benefit from the foundation. A PIF provides confidentiality to beneficiaries such as children, spouses, and charities. For example, a PIF's founder may not want to have publicized that he or she is setting aside assets. Additionally, the beneficiaries may not want their eventual benefit from the foundation to be made public. Arguably, a PIF is like a trust that a PIF can carry out the founder's wishes through the foundation, which may be for personal benefit, charitable purposes, or estate planning. 


\section{CHAPTER 20: STOCK OPTION MANIPULATIONS}

1. Define stock option backdating.

Stock option backdating involves altering the actual date on which the compensation committee granted a stock option to top managers or directors to an earlier date at which the company's stock price was lower. The incentive for the change is that by doing so the backdated stock options can now allow the grantees to buy shares at a lower exercise price, so that they reap larger profits when they sell the shares.

2. Discuss the difference between the opportunistic timing of option and stock option backdating.

Both practices involve manipulating the timing of option grants and can be supported empirically by observing negative abnormal returns before the grant dates and positive abnormal returns after the grant dates. However, compared to the argument that executives can influence the board's decision about the forward-looking date on which they will be awarded options, backdating is associated with retroactive timing of options grants. In other words, backdating takes place when executives already awarded stock options influence the compensation committee to time these grants retroactively to a date in the past when their share price was low.

3. Identify the main cause of stock option manipulations.

The main cause of stock option manipulations is weak corporate governance. For example, studies find that the practice of stock option backdating is more pronounced in firms where boards are chaired by the CEO and dominated by dependent and gray directors.

4. Discuss whether the endorsement of the Sarbanes-Oxley Act (SOX) curbed stock option manipulation.

Before the endorsement of the SOX, the Securities and Exchange Commission previously allowed companies to report the issuance of stock options up to two months after granting the options. That allowed companies to essentially pick the lowest stock price during that twomonth period and report that as the exercise price on the options, giving companies a way to grant instantly profitable options to employees. Today, SOX's Provision 403 requires companies to report option grants to the SEC within two business days. Because the SEC shortened the time lapse between the awarding of grants and filing, Provision 403 has helped 
in eliminating the practice of backdating. However, the practice of springloading continued even after the endorsement of SOX in 2002.

\section{CHAPTER 2 1 : SATYAM SCANDAL}

1. Comment on the governance structure and tone at the top at Satyam and how such a structure fosters fraud.

The Satyam governance structure lacked the most important component of governance - independence - which is critical to establishing checks and balances. The basis of Satyam's corporate governance was nepotism. As a result, the Board of Directors failed to adequately oversee and monitor the management team. Such a governance structure fosters collusion and allows unethical financial reporting to occur and escape detection for extended periods. Satyam's management also lacked integrity. It directed and participated in creating fictitious invoices and bank statements. Such a tone at the top in Satyam signaled to employees that loyalty was more important than integrity and that manipulating accounting records and concealing fraudulent activities was acceptable. Moreover, Satyam's Board lacked financial expertise. As a result, its members may not have understood the consequence and liability for such misreporting, and/or may have been unable to detect or prevent such misreporting.

2. Summarize Raju's rationalization for committing such massive fraudulent reporting and explain why he eventually admitted to the fraud.

Satyam faced a potential takeover attempt by shareholders with substantial ownership should the company report poor financial performance. To avoid such a takeover, Raju first inflated cash and revenues by relatively small amounts. Over time, the gap between real and fictitious cash and revenues became massive. Raju only admitted to this fraud when he could no longer hide this huge gap. In fact, the admission came soon after the failure of an attempted merger, which was the final effort to conceal the fictitious assets.

3. Explain the potential influence of related parties on the Satyam fraud.

Byrraju Ramalinga Raju served as Chairman of the Board and his brother, Rama Raju, served as Managing Director and chief executive officer (CEO). They both exercised direct operational control over all aspects of the company's operations. By definition, the Raju brothers are 
related parties from an independence perspective. Thus, although Satyam's governance structure appeared to have separation between the CEO and Chairman of the Board, it actually made collusion and overriding internal controls a real possibility.

4. Discuss the punishments that Satyam, its executives, PW India, and PW India auditors faced. State and justify whether these punishments were appropriate, too harsh, or too light.

As a result of the huge shareholders' loss (\$450 million in the US market alone), Satyam faced a \$10 million fine from the Securities and Exchange Commission (SEC) and was acquired by another Indian hightech company. Authorities sentenced key former Satyam executives to prison, and Raju received a fine of 50 million Indian Rupees $(\$ 883,960)$. PW India received fines of \$6 million from the SEC, \$1.5 million from PCAOB, and settled a class action lawsuit for $\$ 25.5$ million. Two audit partners received prison sentences. PwC was banned from auditing in India for two years, affecting 75 listed companies, including prestigious Indian publicly listed companies such as Tata Steel and Hindalco Industries.

Some contend these punishments were fair due for the following reasons. First, Satyam and its auditors paid the largest fines ever imposed by the PCAOB and the SEC for foreign-based companies. Second, authorities sentenced eight former Satyam executives and two former auditors to prison. Also, all of the Satyam audit partners were suspended from all work, and $\mathrm{PwC}$ removed the senior audit professionals from client service.

Alternately, given the magnitude of the shareholders' loss, the monetary and nonmonetary punishment of PW India (\$6 million fine by SEC and $\$ 1.5$ million fine by PCAOB, plus the six-month suspension of PW India from accepting new clients) could be considered too light. Professional auditors are required to conduct audits with due care and diligence. The blatant mistakes made by Satyam's auditors directly fostered and allowed the fraud to continue for an extended period of time.

5. Comment on why PW India may have had an incentive to not exercise professional skepticism during their audit of Satyam.

Three possible incentives caused PW India to fail to exercise sufficient professional skepticism in auditing Satyam. 
- Satyam was one of the most prestigious IT service companies in the world and one of the most important clients to PW India. Given the incentive to retain such an important client, PW India auditors had less motivation to challenge their client or request audit adjustment to correct detected misstatement, reducing professional skepticism.

- PW India had been Satyam's auditor since 2000. The longer the auditor-client relationship, the lower is the likelihood/incentive for auditors to challenge its client, reducing professional skepticism.

- Satyam paid high fees to PW India. Between 2003 and 2008, the audit fee earned by PwC from Satyam increased over 300 percent. Other companies in the IT sector did not increase their payments to their auditors to the same extent over this period. $\mathrm{PwC}$ earned an audit fee of about $\$ 878,000$ for the financial year 2007-2008, which is twice the amount spent by other IT companies in the same league on audit fees. Even Tata Consultancy Services, the largest Indian IT company, spent only about $\$ 566,000$ that year.

\section{CHAPTER 22: CORPORATE FRAUD: THE CASES OF BARINGS BANK, VOLKSWAGEN, AND HIH INSURANCE}

1. Discuss the extent of global corporate fraud.

A staggering amount of fraud exists globally. According to the Association of Certified Fraud Examiners, corporate fraud spreads across 125 countries in 23 industry categories equating to $\$ 7$ billion in total losses. In another survey conducted by PwC's Global Economic Crime and Fraud Survey, 49 percent of the respondents claim that corporate fraud has affected their companies.

2. Discuss the international organizations and initiatives that prevent and deter fraud.

Various international organizations try to prevent and deter fraud including the following:

- Stolen Assets Recovery Initiative (StAR). StAR is a joint venture between World Bank and the United Nations Office on Drugs and Crime (UNODC) that helps to stop safe haven for corrupt funds on a global basis. 
- International Criminal Police Organization (INTERPOL). INTERPOL along with other law enforcements host global conferences on money laundering and other financial crimes.

- Financial Action Task Force (FATF). FATF develops policies to curb money laundering internationally.

- Association of Certified Fraud Examiners (ACFE). ACFE provides antifraud training and education globally.

3. Describe the role the Bank of England played in the Barings demise.

The Bank of England had a favored relationship toward Barings Bank. The Bank of England allowed Barings to transfer all its capital outside of the United Kingdom. Nick Leeson needed large sums of capital to undertake risky trades and the Bank of England's relaxed rules for Barings allowing him to gain access to the capital he needed. List the consequences for Volkswagen from its emission scandal.

Several implications stem from the Volkswagen emissions scandal.

- VW set aside $\$ 7.4$ billion for recalls and lawsuits.

- VW faced fines by regulatory authorities and environmental agencies that could eventually exceed $\$ 8$ billion.

- VW experienced a huge drop in share price and sales.

- Authorities indicted both VW and Audi former CEOs on fraud charges and opened an investigation into VW's legal team on charges on destroying evidence.

4. Briefly describe Justice Owen's report with respect to HIH insurance demise.

Justice Owen's report included some important recommendations to avoid further collapse of big institutions. Justice Owen pointed out the relationship between $\mathrm{HIH}$ and Arthur Andersen was one of the important factors leading to the collapse. As per his recommendations, audit partners who are directly involved with a client's audit should not accept any director position or senior management for four years since separating from the audit firm and also to disclose all nonaudit services provided by their audit firms. 


\section{CHAPTER 23: CORPORATE FRAUD: AVENUES FOR FUTURE RESEARCH}

1. Identify the main incentives to commit fraud.

According to the accounting literature on fraud, many incentives exist to commit fraud. These incentives can be classified into self-oriented and organization-oriented incentives. They include increasing compensation, maintaining the firm's credit rating, maintaining an appearance of strong financial performance or masking weak results, and responding to personal financial pressure.

2. Discuss how research in accounting contributes to understanding CEOs' motivations to commit fraud.

Despite the numerous difficulties of conducting research on fraud such as data collection, researchers contribute to the fraud field by exploring and examining financial pressures and incentives for top managers' schemes such as incentives by CEOs and top management to commit fraud and a corporation's financial situation. Researchers also make worthwhile contributions by identifying financial fraud including the most important category of corporate fraud: fraudulent financial statements, misappropriation of assets, and corruption. Moreover, several studies examine the role that corporate governance plays in deterring corporate fraud. These studies highlight the importance of the audit committee, board composition, and external auditors to deter fraud.

3. Define whistleblowing.

Whistleblowing occurs when an organization's members disclose illegal, immoral, or illegitimate practices under the control of their employers, to persons or organizations that may be able to effect action. Several studies and reports show that whistleblowing is the most effective antifraud mechanism.

4. Identify areas for potential future research on fraud.

Despite major advances in academic research to combat fraud, researchers in the accounting discipline have many topics that still require investigation. One area involves the impact of corporate governance on corruption. Although several studies focus on fraudulent financial 
statements, little empirical work investigates corruption. Another research topic is fraud in nonprofit organizations. Having an in-depth examination of the not-for-profit sector is important because the consequences of fraud are severe. As a result of fraud, donor confidence decreases and may result in the organization failing to achieve its objectives. 